\title{
Temperoammonic Stimulation Depotentiates Schaffer Collateral LTP via p38 MAPK Downstream of Adenosine A1 Receptors
}

\author{
(ㄱ) Yukitoshi Izumi ${ }^{1,3,4}$ and $\mathbb{Q}^{-C h a r l e s ~ F . ~ Z o r u m s k i ~}{ }^{1,2,3,4}$ \\ Departments of ${ }^{1}$ Psychiatry, ${ }^{2}$ Neuroscience, ${ }^{3}$ Taylor Family Institute for Innovative Psychiatric Research, and ${ }^{4}$ Center for Brain Research in Mood \\ Disorders, Washington University School of Medicine, St. Louis, Missouri 63110
}

\begin{abstract}
We previously found that low-frequency stimulation of direct temperoammonic (TA) inputs to hippocampal area CA1 depotentiates previously established long-term potentiation in the Schaffer collateral (SC) pathway through complex signaling involving dopamine, endocannabinoids, neuregulin-1, GABA, and adenosine, with adenosine being the most distal modulator identified to date. In the present studies, we examined mechanisms contributing to the effects of adenosine in hippocampal slices from male albino rats. We found that extracellular conversion of ATP to adenosine via an ectonucleotidase contributes significantly to TA-mediated SC depotentiation and the depotentiation resulting from block of adenosine transport. Adenosine-mediated SC depotentiation does not involve activation of c-Jun $\mathrm{N}$-terminal protein kinase, serine phosphatases, or nitric oxide synthase, unlike homosynaptic SC depotentiation. Rather, adenosineinduced depotentiation is inhibited by specific antagonists of p38 MAPK, but not by a structural analog that does not inhibit p38. Additionally, using antagonists with relative selectivity for p38 subtypes, it appears that TA-induced SC depotentiation most likely involves $\mathrm{p} 38$ MAPK $\beta$. These findings have implications for understanding the role of adenosine and other extrahippocampal and intrahippocampal modulators in regulating SC synaptic function and the contributions of these modulators to the cognitive dysfunction associated with neuropsychiatric illnesses.
\end{abstract}

Key words: dopamine; endocannabinoids; GABA; hippocampus; neuregulin; perforant path

\section{Significance Statement}

Low-frequency stimulation of temperoammonic (TA) inputs to stratum lacunosum moleculare of hippocampal area CA1 heterosynaptically depotentiates long-term potentiation of Schaffer collateral (SC) synapses. TA-induced SC depotentiation involves complex signaling including dopamine, endocannabinoids, GABA, and adenosine, with adenosine serving as the most downstream messenger in the cascade identified to date. The present results indicate that TA-induced depotentiation requires intact inputs from entorhinal cortex and that adenosine ultimately drives depotentiation via activation of 338 MAPK. These studies have implications for understanding the cognitive dysfunction of psychiatric illnesses and certain abused drugs.

\section{Introduction}

Changes in the efficacy of excitatory synapses, particularly persistent increases and decreases in transmission such as long-term potentiation (LTP) and long-term depression (LTD), are

Received May 29, 2018; revised Dec. 17, 2018; accepted Dec. 31, 2018.

Author contributions: Y.I. and C.F.Z. designed research; Y.I. performed research; Y.I. and C.F.Z. analyzed data; C.F.Z. wrote the paper.

Work in the authors' laboratory is supported by National Institute of Mental Health Grants MH-101874 and MH-114866, the Taylor Family Institute, and the Bantly Foundation. We thank Kazuko Izumi for technical assistance.

C.F.Z. is a member of the Scientific Advisory Board of Sage Therapeutics. Sage Therapeutics did not fund this research and was not involved in the conduct of this research. The authors declare no other competing financial interests.

Correspondence should be addressed to Charles F. Zorumski at zorumskc@wustl.edu.

https://doi.org/10.1523/JNEUROSCI.1362-18.2018

Copyright $\odot 2019$ the authors $\quad 0270-6474 / 19 / 391783-10 \$ 15.00 / 0$ thought to play key roles in learning and memory (Kandel et al., 2014; Nicoll, 2017). There are, however, limits on the degree to which synapses can increase or decrease their efficacy, and it is important for neurons and synapses to have mechanisms for resetting to baseline levels following successful plasticity and learning. This synaptic resetting can be accomplished by homeostatic mechanisms in which neurons adjust function in response to persistent changes in activity (Turrigiano, 2011). Alternatively, synapses can be reset by homosynaptic or heterosynaptic inputs that instruct the resetting (Fujii et al., 1991; Malenka and Bear, 2004).

We have been interested in understanding whether extrahippocampal inputs can drive depotentiation of previously established LTP, focusing on changes in transmission in the Schaffer 


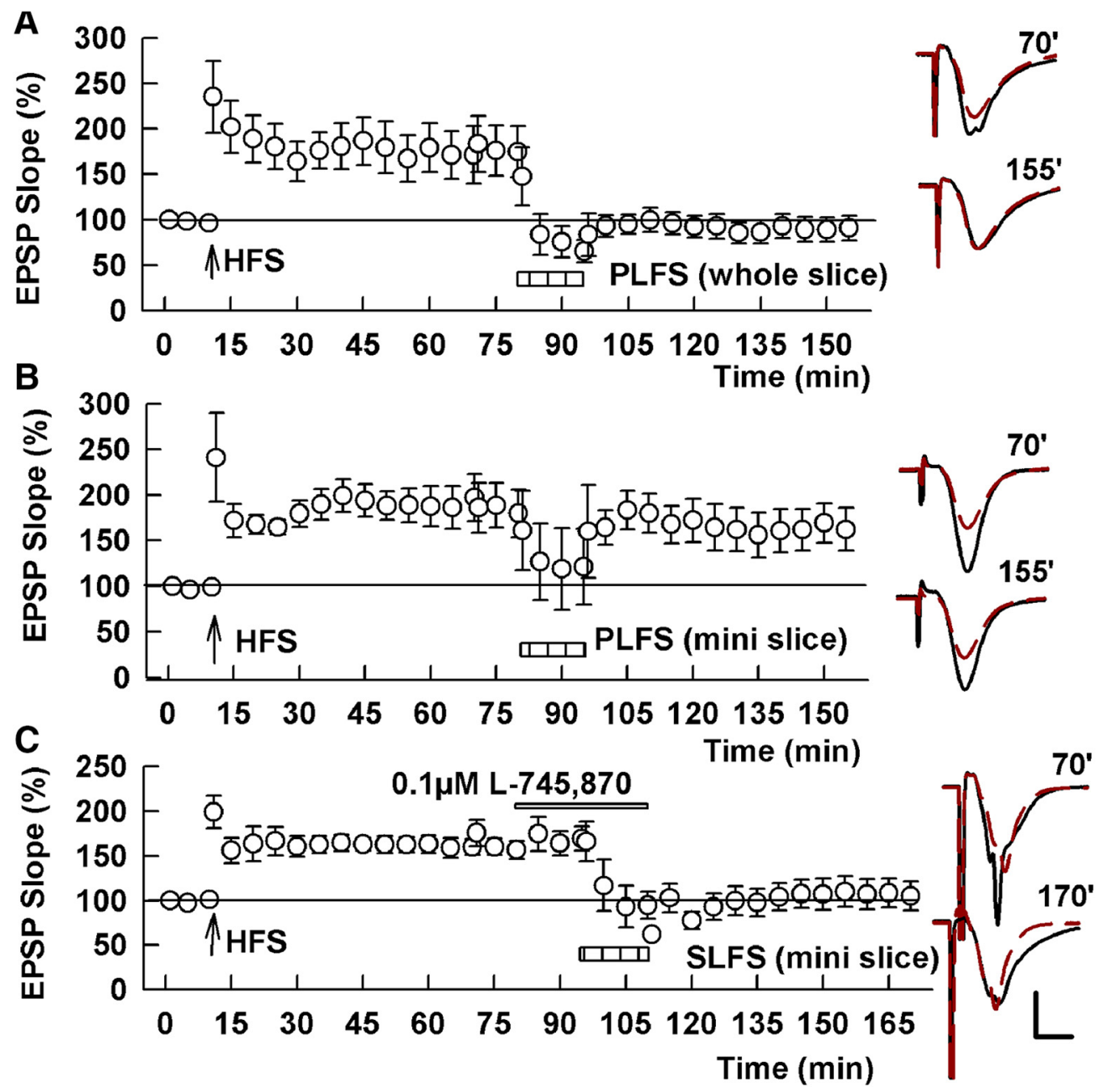

Figure 1. TA-induced SC depotentiation requires inclusion of EC in hippocampal slices. $A$, The graph shows the time course of changes in SC field EPSPs in slices that included EC (whole slice). A single $100 \mathrm{~Hz} \times 1$ s HFS was administered to the SC pathway at the arrow and triggered persisting synaptic enhancement. A $1 \mathrm{~Hz} \times 900$ pulse LFS was delivered to the perforant (temperoammonic) path (PLFS) during the period denoted by the bar. In these slices, LTP was reversed by TA LFS. B, In standard hippocampal slices that do not include EC (mini slice), PLFS failed to depotentiate SC LTP. C, In standard hippocampal slices, the D4R antagonist L-745,870 al so failed to inhibit the depotentiation of SC LTP induced by SC LFS in contrast to what has been shown previously (Kwon et al., 2008; Izumi and Zorumski, 2017). Traces to the right of the graphs show representative EPSPs at the times denoted, with the preceding baseline in red dashed lines and the results 60 min following either HFS or PLSF shown in solid black lines. Calibration: 1 mV, 5 ms.

collateral (SC) pathway in response to direct inputs through the performant [temperoammonic (TA)] path that terminate in stratum lacunosum moleculare (SLM). We have found that repeated low-frequency stimulation (LFS) of TA inputs to SLM reverses SC LTP without persistently altering SC transmission under baseline conditions in naive hippocampal slices (Izumi and Zorumski, 2008). This form of heterosynaptic resetting engages complex signals that include activation of dopamine (DA) D4 receptors (D4Rs), endocannabinoid CB1 receptors (CB1Rs), ErbB4 receptors, $\mathrm{GABA}_{\mathrm{A}}$ receptors $\left(\mathrm{GABA}_{\mathrm{A}} \mathrm{Rs}\right)$, and adenosine A1 receptors (A1Rs), likely in that order (Izumi and Zorumski, 2008, 2016, 2017). The cascade also involves two mitogenactivated protein kinases (MAPKs), ERK1/2, and p38 MAPK (Izumi and Zorumski, 2016).

In the studies outlined above, the activation of A1Rs has been the most distal signal identified to date, in that A1R antagonism blocks the effects of activators of the other receptors involved in SC LTP depotentiation (LTP-D), while antagonists of the other receptors have no effect on the ability of A1R agonists to induce depotentiation (Izumi and Zorumski, 2008, 2016, 2017). In the present studies, we examined the role of other signaling pathways previously linked to SC homosynaptic LTD, LTP-D, and meta- plastic LTP inhibition, including serine protein phosphatases (PPs) and nitric oxide synthase (NOS; Izumi et al., 1992, 2008; Kato et al., 1999; Malenka and Bear, 2004; Zorumski and Izumi, 2012). We also re-examined the role of p38 MAPK based on studies indicating that this kinase can contribute to LTD and depotentiation induced by A1R activation (Fujii et al., 1997, 1999, 2000; Huang et al., 2001).

\section{Materials and Methods}

Hippocampal slices. Protocols for animal use were approved by the Washington University Institutional Animal Care and Use Committee in accordance with national and international guidelines. Hippocampal slices were freshly prepared from the septal (dorsal) hippocampal region of postnatal day 30 (P30) to $\mathrm{P} 34$ male albino rats using previously described methods (Tokuda et al., 2010). Rats were anesthetized with isoflurane and decapitated, and hippocampi were dissected. Isolated hippocampi were placed in ice-cold artificial CSF (ACSF) containing the following (in $\mathrm{mm}$ ): $124 \mathrm{NaCl}, 5 \mathrm{KCl}, 2 \mathrm{MgSO}_{4}, 2 \mathrm{CaCl}_{2}, 1.25 \mathrm{NaH}_{2} \mathrm{PO}_{4}, 22 \mathrm{NaHCO}_{3}$, and 10 glucose, bubbled with $95 \% \mathrm{O}_{2}-5 \% \mathrm{CO}_{2}$ at $4-6^{\circ} \mathrm{C}$, and cut into $450 \mu \mathrm{m}$ slices using a rotary tissue slicer. For some experiments, the slices included a significant portion of entorhinal cortex (EC) to keep TA inputs to SLM in the CA1 region as intact as possible (Izumi and Zorumski, 2008, 2016, 2017). For certain studies in this report, EC was removed, 


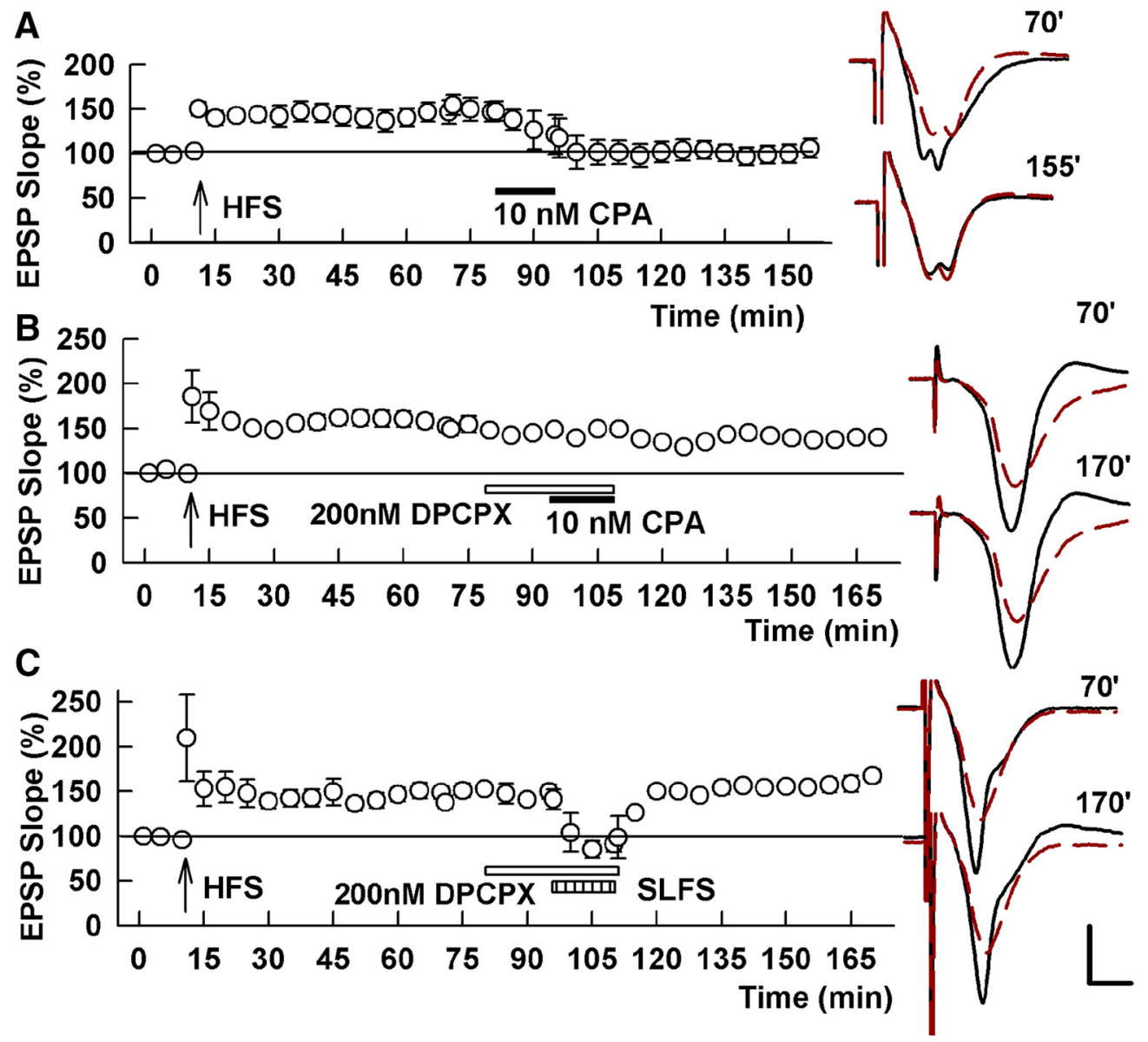

Figure 2. CPA-induced LTP-D in standard hippocampal slices excluding EC. $A$, Perfusion of $10 \mathrm{~nm}$ CPA (black bar), an A1R agonist, readily depotentiated SC TLP. B, The effects of CPA on SC LTP were completely inhibited by the selective A1 receptor antagonist DPCPX (200 nM). C, In mini slices without EC, homosynaptic LTP-D induced by SC LFS is also completely blocked by DPCPX. Traces to the right of the graphs show representative EPSPs at the times denoted as in Figure 1. Calibration: $1 \mathrm{mV}, 5 \mathrm{~ms}$.

allowing focus on chemically induced SC depotentiation in the absence of more intact EC inputs. After preparation, slices were allowed to recover from dissection in an incubation chamber containing gassed ACSF for $1 \mathrm{~h}$ at $30^{\circ} \mathrm{C}$ before experiments.

Hippocampal slice physiology. At the time of the study, slices were transferred individually to a submersion-recording chamber that was maintained at $30^{\circ} \mathrm{C}$ with continuous ACSF perfusion at $2 \mathrm{ml} / \mathrm{min}$. Extracellular recordings were obtained from the apical dendritic layer (stratum radiatum) of the CA1 region for analysis of EPSPs using glass electrodes filled with $2 \mathrm{M} \mathrm{NaCl}$ (5-10 $\mathrm{M} \Omega$ resistance).

EPSPs were evoked using $0.1 \mathrm{~ms}$ constant current pulses through a bipolar stimulating electrode in the SC pathway. For some experiments, a second stimulating electrode was placed in the TA pathway to activate inputs to CA1 in SLM. A control SC input-output (IO) curve was obtained to determine stimulus intensities for subsequent studies. Responses were monitored using the pClamp software (pClamp; RRID: SCR_011323) during an experiment by applying single stimuli to the SC pathway every $60 \mathrm{~s}$ at half-maximal intensity. After establishing a stable baseline for at least $10 \mathrm{~min}, \mathrm{SC}$ LTP was induced by a single $100 \mathrm{~Hz} \times 1 \mathrm{~s}$ high-frequency stimulus (HFS) using the same intensity stimulus. IO curves were repeated $60 \mathrm{~min}$ following tetanic stimulation. TA stimulation to induce SC depotentiation was administered as a single $1 \mathrm{~Hz} \times 15$ min LFS at half-maximal intensity based on prior results (Izumi and Zorumski, 2008, 2016, 2017). Because of infrequent monitoring of synaptic responses, short-term forms of synaptic enhancement following tetanic stimulation are not readily apparent in all figures.

Materials. Chemicals and pharmacological agents were obtained from Tocris Bioscience or Sigma-Aldrich. Concentrations of agents used in this study were based on the literature and on the lack of effect on baseline transmission at the selected concentrations.
Experimental design and statistical analysis. Data were collected and analyzed using PClamp software (Molecular Devices). Data in the text are expressed as the mean \pm SEM. A two-tailed Student's $t$ test was used for comparisons between groups with correction for multiple comparisons when appropriate. Statistical comparisons were based on data from IO curves obtained at baseline and $60 \mathrm{~min}$ following tetanic or $1 \mathrm{~Hz}$ stimulation, with $p<0.05$ considered to be significant. The graphs in all figures display results from the continuous monitoring of synaptic responses during the course of experiments, while the results presented in the text and statistical comparisons are derived from analysis of IO curves, as noted above. Statistical analyses were performed using commercial software (SigmaStat, Systat Software).

\section{Results}

In prior studies, we found that LFS of direct perforant path/TA inputs to SLM (referred to as PLFS in the figures) in the CA1 hippocampal region can reverse previously established LTP at SC synapses without persistently altering baseline transmission in naive slices (Izumi and Zorumski, 2008). Figure $1 A$ shows the ability of PLFS to reverse LTP in control slices. For these studies, we used a hippocampal slice preparation that includes a significant portion of EC, keeping direct inputs to SLM in CA1 as intact as possible (Fig. 1A, "whole slice"; EPSP slopes: $149.5 \pm 5.0 \%$ of baseline $60 \mathrm{~min}$ following SC HFS vs $77.0 \pm 8.9 \% 60 \mathrm{~min}$ following PLFS; $N=7, p=0.000184$ ).

We initially sought to determine whether the inclusion of extrahippocampal structures, including a significant portion of EC, is necessary for this form of LTP-D using a more traditional slice 


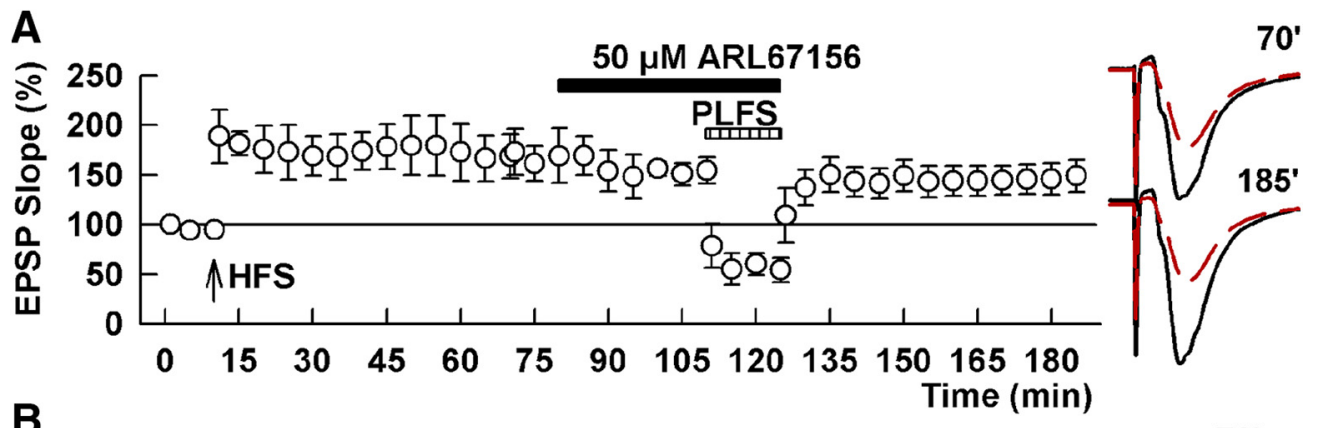

B

Time (min)
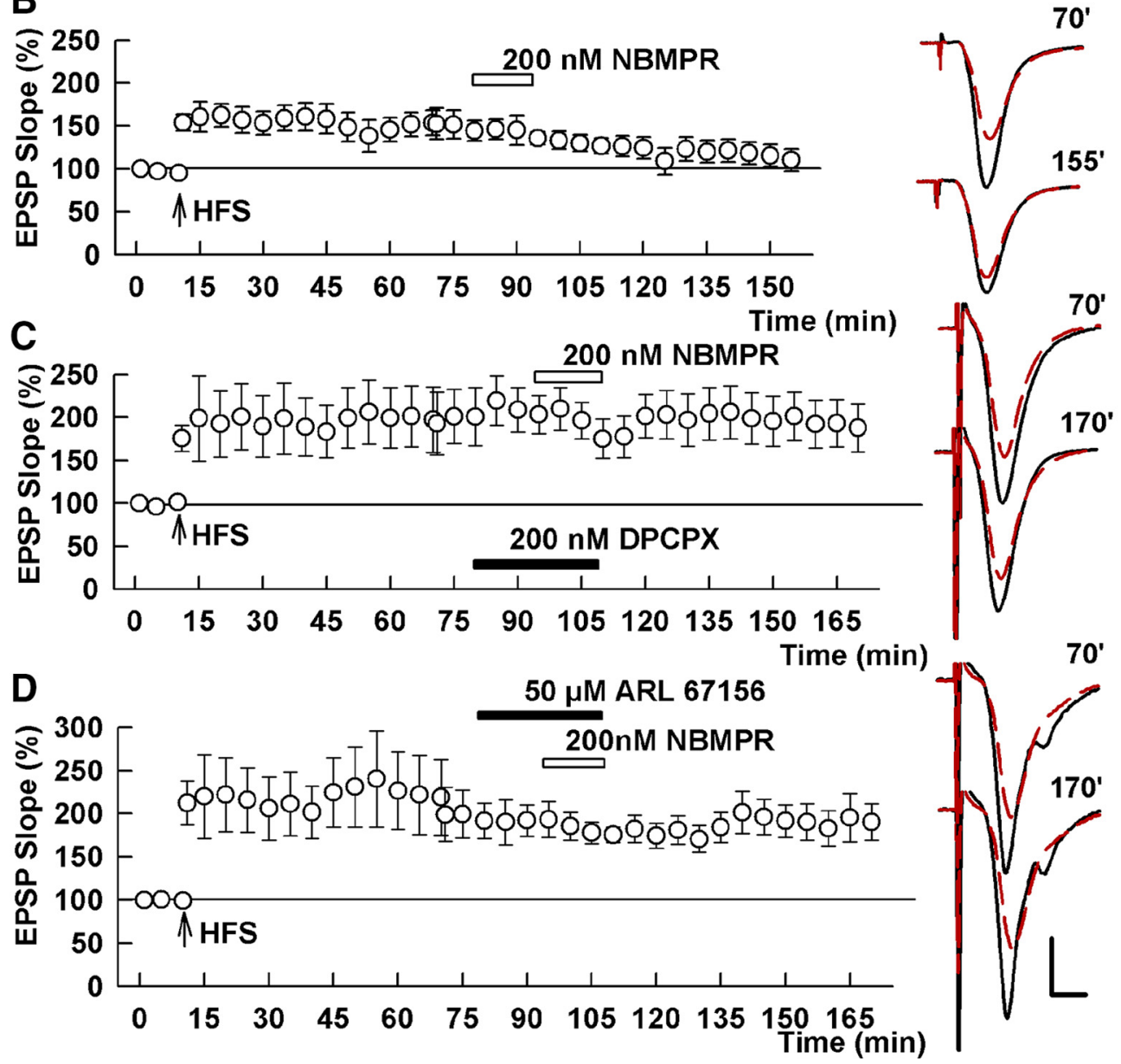

Figure 3. An ectonucleotidase inhibitor but not a nucleoside transport inhibitor, blocks the effects of TA stimulation. All results in this figure were obtained in hippocampal slices containing EC. $A$, In whole slices containing EC, ARL67156 (white bar), a selective ectonucleotidase inhibitor, blocked the effects of TA stimulation on SC LTP. B, A selective nucleoside transport inhibitor, NBMPR, produces a slowly developing depotentiation of SC LTP, consistent with block of uptake of extracellular adenosine. C, Depotentiation induced by NBMPR was blocked by DPCPX. D, Depotentiation by NBMPR was also blocked by ARL67156. Traces show representative EPSPs at the times denoted. Calibration: $1 \mathrm{mV}, 5 \mathrm{~ms}$.

preparation that largely excludes EC (Fig. $1 B$, “mini slice”). In these more restricted slices, we found that TA LFS failed to modify SC LTP (EPSP slopes: $145.3 \pm 12.0 \%$ of baseline $60 \mathrm{~min}$ following SC HFS vs $137.3 \pm 10.2 \% 60 \mathrm{~min}$ following TA LFS, $N=$ $5 ; p=0.5475$; Fig. $1 B$ ).

Our prior studies found that TA-induced SC LTP-D involves activation of dopamine D4Rs and that D4R activation is necessary but not sufficient for this form of depotentiation (Izumi and Zorumski, 2017). Because the removal of EC may also disrupt monoaminergic inputs to area CA1, we examined the effects of the D4R antagonist L-745,870 $(0.1 \mu \mathrm{M}$; Clifford and Waddington, 2000) on homosynaptic SC LTP-D, which also involves D4Rs (Kwon et al., 2008; Izumi and Zorumski, 2017). We found that homosynaptic SC depotentiation remained intact in the more restricted slices, but that this form of LTP-D was not inhibited by L-745,870 (149.1 $\pm 10.5 \%$ of baseline 60 min following SC HFS vs $93.8 \pm 8.9 \% 60$ min following SC LFS, $N=5 ; p=$ 0.00352; Fig. $1 C$ ), in contrast to what we previously observed in slices containing EC (Izumi and Zorumski, 2017). Thus, the disruption of monoaminergic inputs to CA1 may also have contributed to the loss of TA-induced SC LTP-D.

In contrast to the effects of $\mathrm{D} 4 \mathrm{R}$ activation, we previously observed that the activation of adenosine A1Rs is both necessary and sufficient for TA-induced LTP-D, and that adenosine is a downstream regulator of this plasticity with A1R antagonism blocking the effects of more proximal contributors to the cascade of events resulting in SC depotentiation (Izumi and Zorumski, 2016, 2017). We found that even in the more restricted hip- 


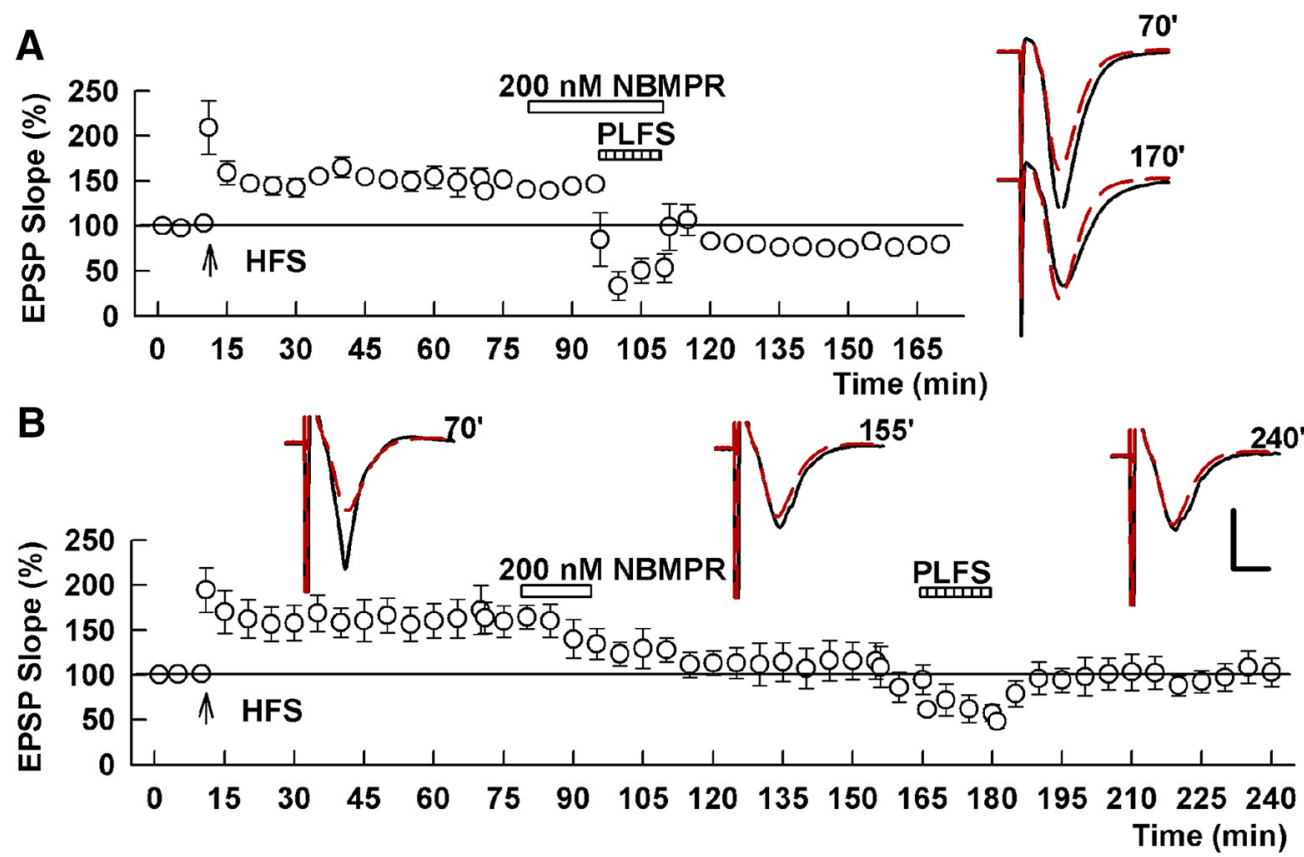

Figure 4. A, In contrast to the ectonucleotidase inhibitor, the nucleoside transport inhibitor NBMPR did not alter the faster occurring depotentiation of SC LTP following TA LFS in slices containing EC. $\boldsymbol{B}$, Despite the failure to block effects of PLFS on SC LTP, depotentiation induced by NBMPR occluded further depotentiation by TA LFS in whole slices, suggesting common mechanisms of action involving adenosine. Traces show representative EPSPs at the times denoted. Calibration: $1 \mathrm{mV}, 5 \mathrm{~ms}$.

pocampal (mini) slices, $10 \mathrm{~nm} \mathrm{~N}^{6}$-cyclopentyladenosine (CPA), a selective A1R agonist, effectively and persistently reversed SC LTP $(141.2 \pm 8.0 \% 60 \mathrm{~min}$ following SC HFS vs $70.3 \pm 3.1 \% 60$ min following CPA; $N=5, p=0.000191$; Fig. $2 A$ ). We also found that CPA-induced depotentiation was completely eliminated by the selective A1 receptor antagonist, 1,3-dipropyl-8-cyclopentylxanthine (DPCPX; $152.5 \pm 2.3 \%$ of baseline $60 \mathrm{~min}$ following SC HFS vs $146.4 \pm 9.0 \% 60 \mathrm{~min}$ following CPA + DPCPX; $N=5, p=0.4432$; Fig. $2 B$ ), consistent with what we previously found for TA-induced SC LTP-D (Izumi and Zorumski, 2008). Similarly, and consistent with prior reports (Fujii et al., 1997; Santschi et al., 2006), we found that DPCPX also blocked the ability of homosynaptic SC LFS to depotentiate SC LTP in traditional hippocampal slices $(143.1 \pm 9.7 \%$ of baseline $60 \mathrm{~min}$ following SC HFS vs $161.4 \pm 9.3 \% 60$ min following SC LFS + DPCPX; $N=5, p=0.1022$; Fig. $2 C$ ).

There are two primary sources of adenosine that could contribute to LTP-D: release of adenosine itself and/or extracellular conversion from ATP (Pascual et al., 2005). If extracellular ATP is the source of adenosine, an ectonucleotidase inhibitor should block the effects of TA stimulation. Consistent with this, we found that $50 \mu \mathrm{M}$ ARL67156 inhibited TA-induced LTP-D in slices containing EC $(166.7 \pm 15.7 \%$ of baseline following SC HFS vs $164.5 \pm 15.2 \%$ after TA LFS; $N=5, p=0.4435$; Fig. $3 A$ ). In contrast, $S$-(4-nitrobenzyl)-6-thioinosine (NBMPR; $200 \mathrm{nM}$ ), a selective inhibitor of equilibrative nucleoside (adenosine) transporter 1 (ENT-1), produced a slowly developing dampening of SC LTP when administered in the absence of TA stimulation $(162.2 \pm 10.3 \%$ after SC HFS vs $124.4 \pm 13.0 \% 60$ min after NBMPR; $N=6, p=0.0486$; Fig. $3 B$ ). Consistent with NBMPR promoting the accumulation of extracellular adenosine, we found that NBMPR-induced depotentiation was blocked by DPCPX (152.6 $\pm 12.6 \%$ of baseline $60 \mathrm{~min}$ after SC HFS vs $144.6 \pm 4.9 \% 60 \mathrm{~min}$ following NBMPR plus DPCPX; $N=5 ; p=$ 0.6416; Fig. 3C). Depotentiation by NBMPR was also blocked by ARL67156, supporting the idea that the conversion of ATP to adenosine is important for this form of synaptic resetting $(170.1 \pm 11.3 \% 60 \mathrm{~min}$ after SC HFS vs $164.5 \pm 10.3 \% 60 \mathrm{~min}$ after NBMPR plus ARL67156; $N=5 ; p=0.4683$; Fig. $3 D$ ). NBMPR, however, failed to alter either the acute or prolonged effects of TA stimulation $(165.3 \pm 14.3 \% 60 \mathrm{~min}$ following SC HFS vs $78.3 \pm 8.2 \% 60$ min following TA LFS; $N=5 ; p=0.0051$; Fig. $4 A$ ), suggesting that the release of adenosine via ENT-1 did not contribute significantly to the effects of TA stimulation. Additionally, NBMPR did not promote the ability of TA stimulation to depotentiate SC LTP in mini slices not including entorhinal cortex (142.6 $\pm 8.0 \%$ of baseline $60 \mathrm{~min}$ following SC HFS vs $135.6 \pm 6.8 \% 60 \mathrm{~min}$ following TA LFS; $N=5 ; p=0.5237$ ). Nonetheless, depotentiation induced by NBMPR occluded further depotentiation by TA stimulation in whole slices [168.8 \pm $14.7 \% 60 \mathrm{~min}$ following SC HFS vs $77.4 \pm 15.4 \% 60 \mathrm{~min}$ following NBMPR $(p=0.0026)$ vs $78.6 \pm 16.0 \%$ following TA stimulation ( $p=0.9582$ vs NBMPR); $N=5$; Fig. $4 B]$.

To date, our studies have not revealed mechanisms contributing to the effects A1Rs in the depotentiation process. Thus, in the following experiments, we examined potential mechanisms contributing to adenosine-mediated SC depotentiation, focusing on pathways previously linked to depotentiation and adenosineinduced synaptic depression. Based on prior studies showing that serine-threonine PPs play important roles in homosynaptic SC LTD, metaplastic LTP inhibition, and depotentiation of SC LTP (Izumi et al., 1992, 2008; Malenka and Bear, 2004), we examined the role of these phosphatases in the effects of CPA. In contrast to homosynaptic depotentiation in the SC pathway, we found that specific inhibitors of PP1, PP2A, and PP2B failed to reverse CPAinduced depotentiation of SC LTP (Fig. 5A,B). Specifically, 20 $\mu \mathrm{M}$ okadaic acid, an inhibitor of PP1 and PP2A (McCluskey et al., 2002), failed to inhibit CPA-induced LTP-D (175.8 $\pm 13.4 \% 60$ min following SC HFS vs $70.6 \pm 13.0 \% 60$ min following CPA; $N=5 ; p=0.000678)$. Similarly, $1 \mu \mathrm{M}$ FK-506, an inhibitor of PP2B (Ho et al., 1996) also failed to overcome CPA (179.0 \pm $16.7 \%$ vs $101.4 \pm 22.7 \% ; N=5 ; p=0.0336$ ). We also found that 

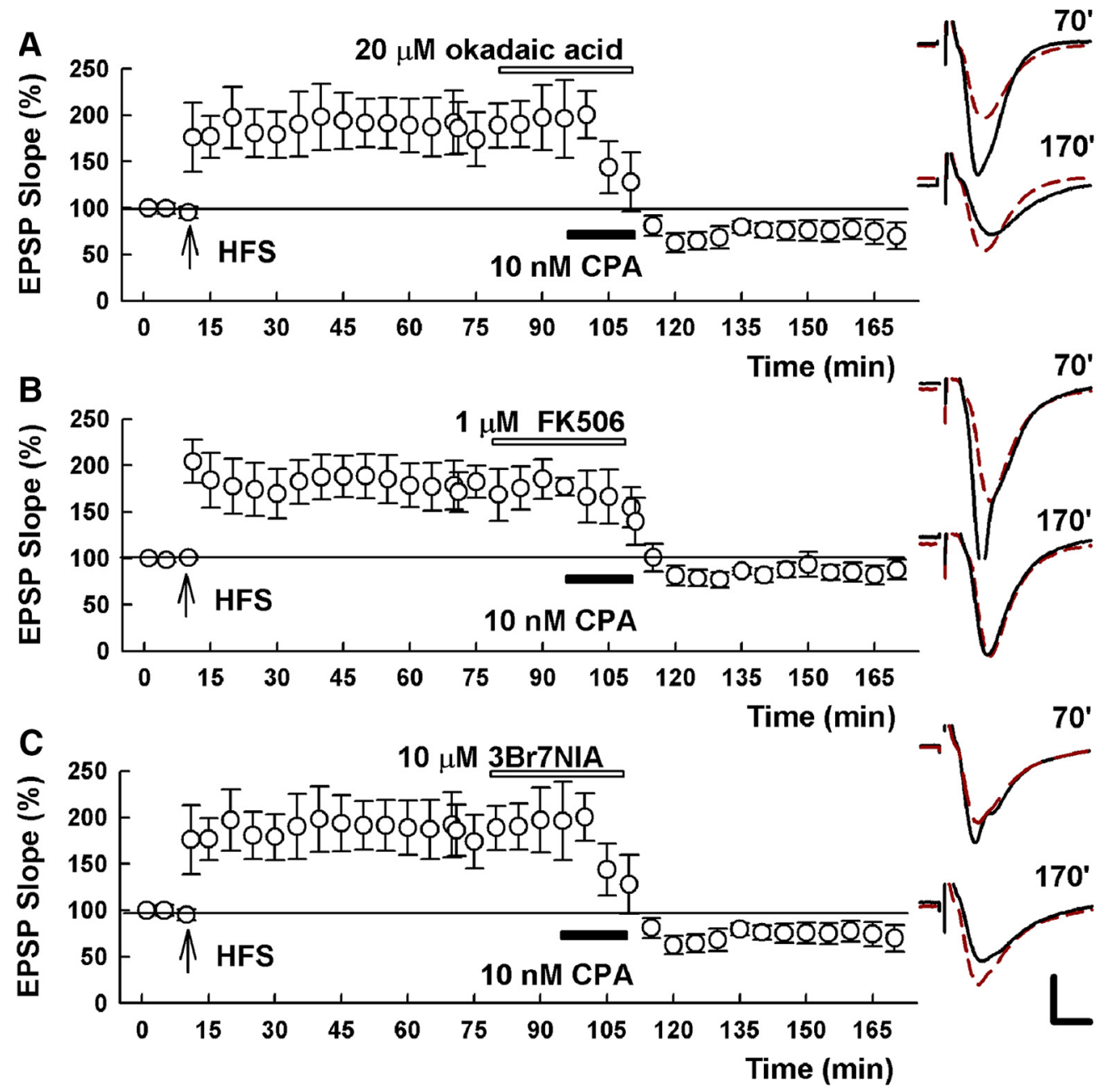

Figure 5. CPA-induced depotentiation does not involve serine phosphatases or NOS.A, Administration of $20 \mu \mathrm{m}$ okadaic acid (white bar), an inhibitor of PP1 and PP2A, had no effect on the ability of CPA (black bar) to depotentiate SC LTP. B, Similar to okadaic acid, $1 \mu \mathrm{m}$ FK506 (white bar) had no effect on CPA-induced depotentiation. C, In the presence of a broad-spectrum N0S antagonist, 3Br7NIA, CPA still depotentiated SC LTP. Traces show representative waveforms as in Figure 1.

3-bromo-7-nitro-indazole (3Br7NIA), a broad-spectrum inhibitor of NOSs (Bland-Ward and Moore, 1995), had no effect on CPA-induced depotentiation (180.2 $\pm 27.5 \%$ vs $90.0 \pm 15.3 \%$; $N=5 ; p=0.036$; Fig. $5 C$ ), again in contrast to the role of NOS in SC LTD, metaplasticity; and depotentiation (Izumi et al., 1992; Izumi and Zorumski, 1993).

Although we previously found that a specific inhibitor of c-jun-N-terminal kinase (JNK) had no effect on TA-induced LTP-D (Izumi and Zorumski, 2016), we also examined whether JNK contributes to CPA-induced depotentiation of SC LTPbased on studies indicating that this kinase contributes to A1Rmediated LTD (Brust et al., 2007; Chen et al., 2014). SP600125 is a broad-spectrum inhibitor for JNK1, JNK2, and JNK3 with $\mathrm{IC}_{50}$ values of 40, 40, and $90 \mathrm{nM}$, respectively (Bennett et al., 2001). In the presence of $10 \mu \mathrm{M}$ SP600125, CPA readily induced depotentiation $(160.5 \pm 16.5 \% 60 \mathrm{~min}$ after HFS and $90.7 \pm 8.5 \% 60 \mathrm{~min}$ after CPA administration; $N=5 ; p=0.035$, paired $t$ test; Fig. $6 A$ ).

Because prior studies of adenosine-induced LTD have indicated a role for p38 MAPK (Brust et al., 2006, 2007), we examined the effects of specific p38 inhibitors. In our earlier studies, we found that $1 \mu \mathrm{M}$ SB203580, a p38 inhibitor, blocked TA-induced LTP-D but did not alter CPA-induced depotentiation, suggesting that p38 activation occurs upstream of A1Rs (Izumi and Zorumski, 2016). We re-examined this issue using higher concentra- tions of SB203580 and other p38 inhibitors. We found that $10 \mu \mathrm{M}$ $(154.8 \pm 8.5 \%$ vs $148.7 \pm 8.4 \% ; N=5$; Fig. $6 B)$ and $20 \mu \mathrm{M}$ $(146.6 \pm 6.3 \%$ vs $147.8 \pm 7.1 \% ; N=5$; data not shown) SB203580 effectively blocked the effects of $10 \mathrm{nM} \mathrm{CPA}[p=$ $0.0000223(10 \mu \mathrm{M})$ and $p=0.00000845(20 \mu \mathrm{M})$, respectively, against CPA alone], but had no effect at $1 \mu \mathrm{M}(131.9 \pm 6.4 \%$ vs $81.8 \pm 17.2 \% ; N=5 ; p=0.019 ;$ Fig. $6 B)$. At $10 \mu \mathrm{M}, \mathrm{SB} 202474$, an analog of SB203580 that is inactive against p38 MAPK (Davies et al., 2000), also failed to block CPA-induced LTP-D (140.6 \pm $13.5 \%$ vs $80.6 \pm 10.2 \% ; N=5 ; p=0.0048$; Fig. $6 C$ ), supporting the hypothesis that the effects of SB203580 involve p38 inhibition.

SB203580 is a relatively selective inhibitor of $\alpha$ and $\beta$ p38 MAPK subtypes. To provide further support for a role of $\mathrm{p} 38 \mathrm{MAPK}$ acting downstream of CPA, we examined two other p38 MAPK inhibitors. At $1 \mu \mathrm{M}, \mathrm{SB} 202190$, an inhibitor of $\mathrm{p} 38 \alpha$ and $\beta$ but not p38 $\gamma$ or $\delta$ (Davies et al., 2000), dampened, but did not completely eliminate, the effects of CPA on SC LTP $(147.1 \pm 5.9 \%$ of baseline $60 \mathrm{~min}$ after SC HFS vs $130.7 \pm 5.5 \% 60 \mathrm{~min}$ after CPA; $p=0.0344$ by paired $t$ test; $N=5$; Fig. $7 A$ ). Despite the reduction in LTP magnitude, the observed degree of potentiation is greater than the value with CPA alone ( $p=0.000012$ vs CPA alone). In contrast, $0.1 \mu \mathrm{M}$ skepinone-L, a potent inhibitor of p38 $\alpha$ (Koeberle et al., 2011), had no effect on CPA-induced LTP-D (168.3 \pm $24.2 \% 60 \mathrm{~min}$ after HFS vs $74.7 \pm 9.4 \%$ after CPA; $p=0.0206$; 


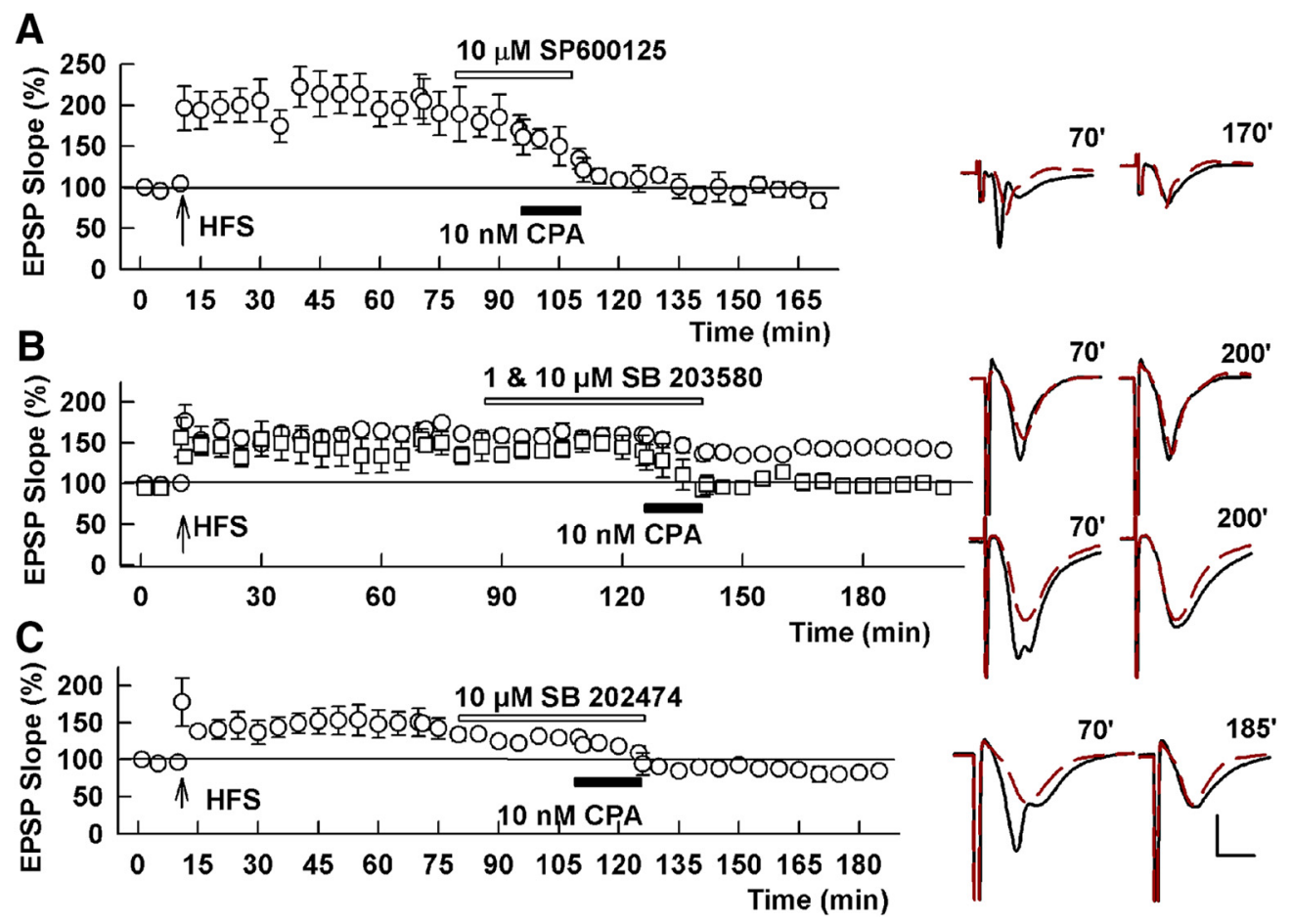

Figure 6. p38 MAPK, but not JNK, contributes to effects of CPA on SC LTP. A, The effects of CPA on SC LTP were not blocked by $10 \mu \mathrm{M}$ SP600125, a broad-spectrum JNK inhibitor. Drugs were administered for the periods denoted by the bars. B, At $1 \mu \mathrm{m}$ SB203580, a p38 MAPK antagonist, had no effect on the ability of CPA to depotentiate SC LTP (white circles). We previously found that $1 \mu \mathrm{m} \mathrm{SB203580} \mathrm{reversed} \mathrm{TA-induced} \mathrm{LTP-D} \mathrm{(Izumi} \mathrm{and} \mathrm{Zorumski,} \mathrm{2016).} \mathrm{In} \mathrm{contrast,} 10 \mu \mathrm{m}$ SB203580 blocked the effects of $10 \mathrm{~nm}$ CPA (white squares). C, An inactive structural analog of SB203580, SB202474, failed to alter the effects of CPA on SC LTP. Traces show EPSPs at the times denoted as in Figure 1. Calibration: $1 \mathrm{mV}, 5 \mathrm{~ms}$.

$N=5$; Fig. $7 B$ ). However, we found that $0.1 \mu \mathrm{M}$ skepinone- $\mathrm{L}$ completely eliminated the effects of TA stimulation (PLFS) on SC LTP in slices that contained intact EC inputs $(183 \pm 8.3 \%$ change in SC EPSPs 60 min following SC HFS vs $178.2 \pm 8.3 \%$ change $60 \mathrm{~min}$ after TA LFS; $N=5 ; p=0.00836$, compared with CPA in the presence of skepinone; Fig. $7 C$ ). These latter results indicate that, while CPA and TA stimulation have overlapping features, TA-induced LTP-D is not identical to CPAinduced SC LTP-D.

\section{Discussion}

In this report, we provide further information about mechanisms contributing to the depotentiation of SC LTP following LFS of TA inputs to SLM in area CA1. The present results indicate three major points about the complex cascade of events resulting in TA-induced LTP-D. First, the induction of TA-induced LTP-D requires intact inputs in SLM, as evidenced by results showing that the removal of EC in the slicing procedure eliminates this form of synaptic resetting. It is unclear whether the key inputs involve direct excitatory or inhibitory paths from EC itself or other inputs that enter the hippocampus via SLM (Basu et al., 2016), including monoaminergic inputs from midbrain and brainstem (Swanson and Hartman, 1975; Smith and Greene, 2012). Our results showing that the removal of EC also disrupts the involvement of D4Rs in homosynaptic SC LTP-D suggest that inputs that activate these receptors, either DA itself or perhaps norepinephrine (NE; Smith and Greene, 2012; Root et al., 2015; Sánchez-Soto et al., 2016) have also been altered. We cannot, however, exclude the possibility that TA stimulation drives back propagating action potentials in extrahippocampal inputs. It also appears that TA stimulation in slices with severed extrahippocampal inputs failed to promote sufficient accumulation of adenosine for this form of depotentiation, even in the presence of a nucleoside transport inhibitor. Yet, the more restricted slice preparation does not alter the ability of an exogenous A1R agonist to promote chemically induced SC synaptic resetting.

Second, unlike homosynaptic LTD or LTP-D (Izumi et al., 1992; Izumi and Zorumski, 1993), we found no evidence that A1R-mediated SC LTP-D involves JNK, serine phosphatases or NOS. Third, our results indicate that A1R-mediated depotentiation, like TA-induced SC LTP-D, involves the activation of p38 MAPK, likely downstream of A1R activation. This latter result is consistent with previously described roles of p38 MAPK in LTD resulting from A1R activation (Brust et al., 2006, 2007; Chen et al., 2014). Based on the effects of inhibitors with differing potencies on $\mathrm{p} 38$ MAPK subtypes, it appears that the p38 $\beta$ subtype is a prime contributor to the effects of CPA. CPA-induced depotentiation, however, is not identical to TA-induced SC LTP-D based on the effects of skepinone-L, an agent with selectivity for p38 $\alpha$ (Koeberle et al., 2011) that inhibited the effects of TA stimulation but had no effect on CPA. This latter observation could reflect the possibility that adenosine released in response to TA stimulation is more restricted than bath applications of the agonist CPA and results in the activation of A1Rs that differ in coupling to p38 isoforms. Differential activation of p38 MAPK isoforms can result from differences in the coupling of receptors to MAPK kinase subtypes, as has been shown in other systems (Cuenda and Rousseau, 2007; Feng et al., 2009). Resolution of this issue will require studies of animals with conditional elimination of specific p38 isoforms. Nonetheless, A1R and p38 MAPK activation are clearly downstream events in the cascade leading to TA-induced synaptic resetting.

Prior studies have provided strong evidence that adenosine contributes to chemical and heterosynaptic LTD (Zhang et al., 2003; 
A
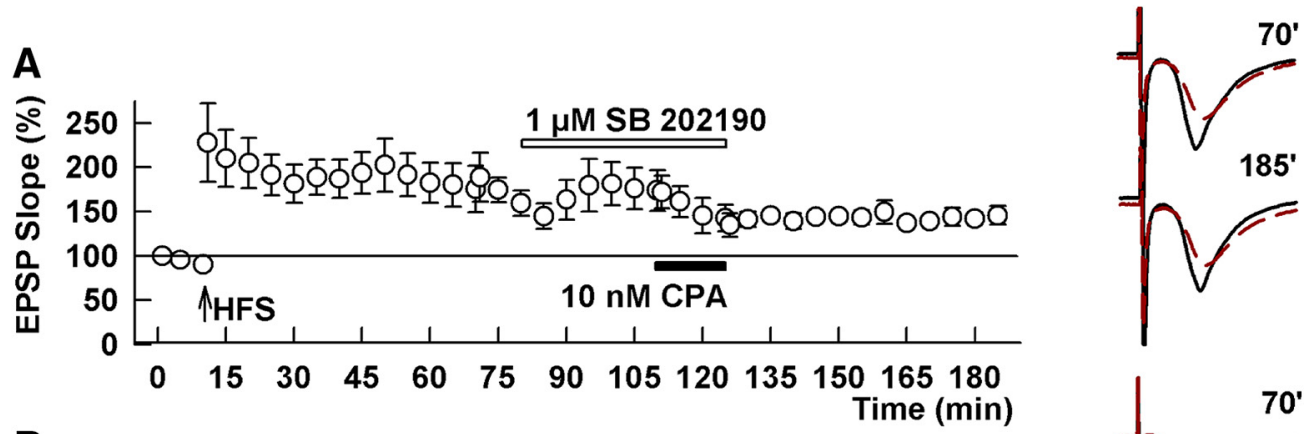

B

$0.1 \mu \mathrm{M}$ skepinone
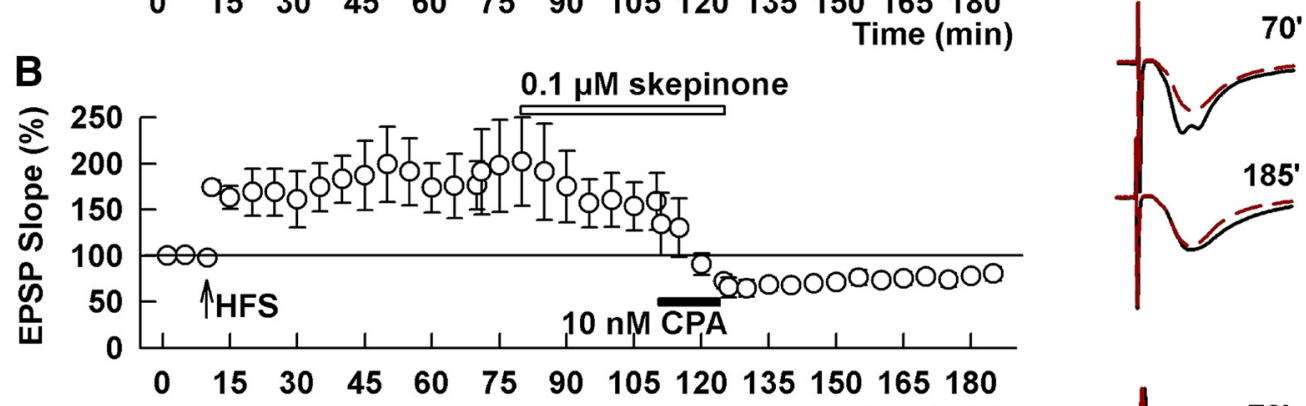

C

$0.1 \mu \mathrm{M}$ skepinone
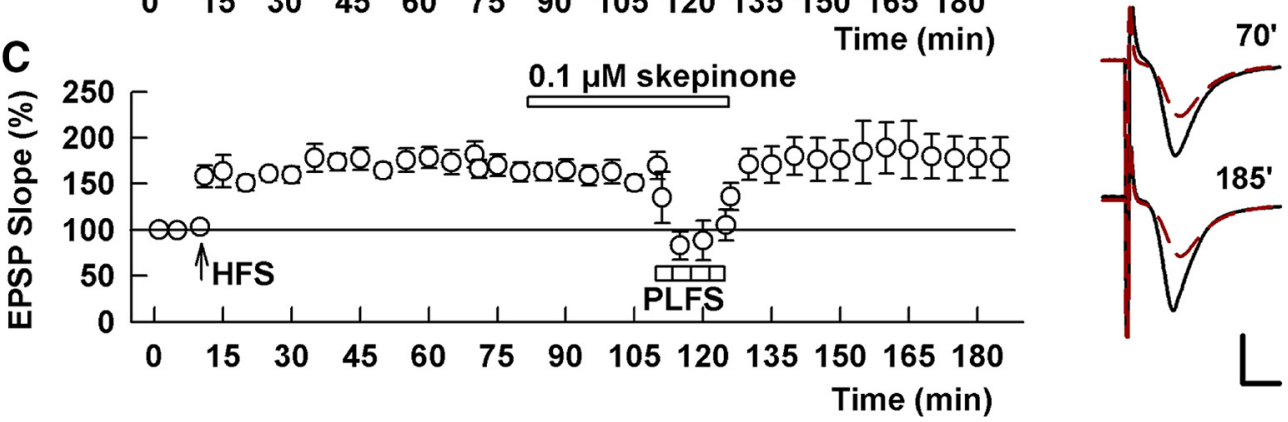

Figure 7. The effects of CPA on SCLTP involve specific 38 MAPK subtypes. A, SB202190, a p38 inhibitor that blocks both p38 MAPK $\alpha$ and $\beta$, dampens the effects of CPA on SC LTP. B, Skepinone-L, a 338 inhibitor with relative selectivity for p38 $\alpha$, failed to alter the effects of CPA. C, In contrast, the same concentration of skepinone-L completely blocked the effects of TA LFS on SC LTP. Traces show EPSPs at the times denoted as in Figure 1. Calibration: $1 \mathrm{mV}, 5 \mathrm{~ms}$.

\title{
Model for PP (TA)-induced Depotentiation
}

\author{
PP (TA) Stimulation @ 1Hz x 900 pulses \\ Dopamine $\rightarrow \stackrel{\downarrow}{\text { D4Rs }} \rightarrow$ ERK $1 / 2$ \\ $\downarrow$ \\ Diacylglycerol lipase $\rightarrow$ 2AG $\rightarrow$ CB1R \\ $\downarrow$ \\ $\mathrm{Nrg}-1 \rightarrow \mathrm{ErbB}$ \\ $\downarrow$ \\ $\mathrm{GABA} \rightarrow \mathrm{GABA}_{\mathrm{A}} \mathrm{Rs}$ \\ ATP (ARL67156) $\rightarrow$ Adenosine (CPA) $\rightarrow$ A1R (DPCPX) \\ $\downarrow$ \\ p38MAPK (SB203580; SB202190; skepinone-L) \\ $\downarrow$

\section{SC Depotentiation}

Figure 8. The diagram depicts contributors to TA-induced SC LTP-D based on present results and prior studies in whole slices containing EC. The present study indicates that adenosine accumulation results from ATP degradation via ectonucleotidases and that activation of $\mathrm{p} 38$ MAPK occurs downstream of A1Rs. Data in this manuscript further indicate that CPA- and TA-induced LTP-D have overlapping features but are not identical with regard to the involvement of 338 MAPK subtypes. (PA (in green) is an A1R agonist that promotes SC depotentiation chemically, while the A1R antagonist DPCPX (in red) blocks LTP-D. The ectonucleotidase inhibitor ARL67156 and the two p38 MAPK inhibitors block LTP-D and are shown in red. 
Pascual et al., 2005; Brust et al., 2006, 2007; Santschi et al., 2006; Serrano et al., 2006; Chen et al., 2013, 2014; Boddum et al., 2016) and depotentiation of glutamatergic synapses via activation of A1Rs (Staubli and Chun, 1996; Abraham and Huggett, 1997; de Mendonça et al., 1997; Fujii et al., 1997; Huang et al., 1999, 2001). The source of adenosine for this plasticity is not always certain, although, in multiple studies, it has involved the release of ATP from astrocytes with extracellular conversion to adenosine (Pascual et al., 2005; Serrano et al., 2006; Boddum et al., 2016). Additionally, ATP itself can depress glutamate-mediated transmission in some studies (Zhang et al., 2003; Chen et al., 2013). Our present results are consistent with extracellular ATP serving as a major, although not necessarily exclusive, source of adenosine underlying TA-induced SC depotentiation. Interestingly, two key upstream mediators involved in TA-induced SC-LTP-D, endocannabinoids and GABA, can promote increases in astrocytic intracellular calcium that contribute to ATP release and adenosine accumulation (Serrano et al., 2006; Boddum et al., 2016; Covelo and Araque, 2018). In our prior studies, we found that endocannabinoids act via $\mathrm{CB} 1 \mathrm{Rs}$ and $\mathrm{GABA}_{\mathrm{A}} \mathrm{Rs}$, respectively (Izumi and Zorumski, 2016), but the cellular localization of the key receptors is not certain.

A1Rs have several presynaptic and postsynaptic mechanisms that could contribute to LTD and depotentiation. These mechanisms include the activation of serine phosphatases, including PP1 (Huang et al., 1999, 2001) and PP2A (Huang et al., 1999; Brust et al., 2006; Chen et al., 2014), but not PP2B (Huang et al., 2001). Additionally, PP2B contributes to homosynaptic LTD (Malenka and Bear, 2004) and metaplasticity (Kato et al., 1999; Izumi et al., 2008). In our present studies, inhibitors of these phosphatases had no effect on CPA-mediated LTP-D. A1Rs also activate MAPKs, and these kinases, particularly p38 MAPK (Chen et al., 2014) and JNK (Brust et al., 2007; Chen et al., 2014), participate in A1R-mediated LTD. In our prior work, we found no effects of JNK inhibition on TA-induced SC LTP-D, unlike other forms of LTP-D (Zhang et al., 2018), but we did find a role for p38 MAPK (Izumi and Zorumski, 2016). In the present studies, we provide evidence that the activation of p38 likely occurs downstream of A1R activation and involves the $\beta$ p38 MAPK subtype. How p38 activation drives depotentiation remains uncertain, although the effects on clathrin-mediated endocytosis of AMPA receptors (Chen et al., 2014), and possibly persistent presynaptic effects (Pascual et al., 2005; Boddum et al., 2016), could contribute.

These results indicate that TA-induced SC depotentiation requires extrahippocampal inputs as well as intrahippocampal circuits and processing. A role for the activation of D4Rs in SC depotentiation has now been shown for depotentiation resulting from either homosynaptic SC stimulation (Kwon et al., 2008; Izumi and Zorumski, 2017) or TA-mediated heterosynaptic resetting (Izumi and Zorumski, 2017). It is unclear whether the disruption of TA-induced LTP-D by removal of EC results strictly from the loss of EC inputs or the disruption of other inputs that enter the hippocampus via SLM. In prior studies, we found no role for NMDA, AMPA, or metabotropic glutamate receptors in the process, suggesting that excitatory inputs from EC are unlikely to be key mediators (Izumi and Zorumski, 2008, 2016). EC can also provide longer-range GABAergic inputs to hippocampus (Basu et al., 2016), and $\mathrm{GABA}_{\mathrm{A}} \mathrm{R}$ activation participates in the depotentiation process (Izumi and Zorumski, 2016); these inputs would be altered by the removal of EC. It is also likely that interneurons within the CA1 region participate in synaptic resetting, but the identity of these interneurons is not certain. Given the role of D4Rs, CB1Rs, and ErbB4 in the depotentiation scheme, it is possible that the effects on parvalbumin-positive interneurons play a key role given that their activity can be modulated by these receptors (Mrzljak et al., 1996; Woo et al., 2007; Vullhorst et al., 2009; Neddens and Buonanno, 2010; Shamir et al., 2012). Other possibilities include cholecystokinin interneurons that are modulated by neuregulin 1 and ErbB4 receptors (Neddens and Buonanno, 2010).

Combined with prior results, we suggest the following scheme for TA-induced SC depotentiation. Proximal signals driven by LFS of TA inputs to SLM result in the activation of D4Rs likely via either DA or NE (Smith and Greene, 2012; Root et al., 2015) and provide a necessary but not sufficient signal in the pathway. Activation of ERK1/2 occurs early in the cascade. Subsequent events involve the release of an endocannabinoid agonist, likely 2-arachidonylglycerol, and stimulation of CB1Rs. This is followed by the release of NRG-1 and activation of ErbB4 receptors with activation of $\mathrm{GABA}_{\mathrm{A}}$ Rs. Further downstream, A1Rs are activated and provide a signal that results in p38 MAPK and changes in SC-mediated transmission (Izumi and Zorumski, 2016, 2017; Fig. 8).

TA-induced SC LTP-D represents a novel form of heterosynaptic plasticity in which extrahippocampal inputs via SLM instruct the resetting of SC synapses following successful and stable induction of LTP. There are several unique features of TAinduced SC depotentiation, including the observation that TA LFS has no persisting effect on baseline SC transmission in contrast to homosynaptic SC LFS (Izumi and Zorumski, 2008). Furthermore, and again unlike homosynaptic SC LFS, TA LFS does not inhibit subsequent LTP in the SC pathway (Izumi and Zorumski, 2008; Izumi et al., 2013) and does not involve the activation of NMDARs or neurosteroid synthesis (Izumi and Zorumski, 2008, 2016). TA-induced LTP-D also does not involve serine phosphatases or NOS. Given the involvement of multiple neuromodulators in the process and the ability of specific receptor agonists to trigger depotentiation, this form of synaptic resetting is positioned to possibly play a key role in several neuropsychiatric disorders, including major depression, bipolar disorder, schizophrenia, and substance use disorders. While the role of this form of plasticity in cognitive function and behavior remains unknown, induction of this form of plasticity could contribute to cognitive dysfunction across a range of illnesses.

\section{References}

Abraham WC, Huggett A (1997) Induction and reversal of long-term potentiation by repeated high-frequency stimulation in rat hippocampal slices. Hippocampus 7:137-145.

Basu J, Zaremba JD, Cheung SK, Hitti FL, Zemelman BV, Losonczy A, Siegelbaum SA (2016) Gating of hippocampal activity, plasticity, and memory by entorhinal cortex long-range inhibition. Science 351:aaa5694.

Bennett BL, Sasaki DT, Murray BW, O’Leary EC, Sakata ST, Xu W, Leisten JC, Motiwala A, Pierce S, Satoh Y, Bhagwat SS, Manning AM, Anderson DW (2001) SP600125, an anthrapyrazolone inhibitor of jun N-terminal kinase. Proc Natl Acad Sci U S A 98:13681-13686.

Bland-Ward PA, Moore PK (1995) 7-Nitro indazole derivatives are potent inhibitors of brain, endothelium and inducible isoforms of nitric oxide synthase. Life Sci 57:PL131-PL135.

Boddum K, Jensen TP, Magloire V, Kristiansen U, Rusakov DA, Pavlov I, Walker MC (2016) Astrocytic GABA transporter activity modulates excitatory neurotransmission. Nat Commun 7:13572.

Brust TB, Cayabyab FS, Zhou N, MacVicar BA (2006) p38 mitogenactivated protein kinase contributes to adenosine Al receptor-mediated synaptic depression in area CA1 of the rat hippocampus. J Neurosci 26 : 12427-12438

Brust TB, Cayabyab FS, MacVicar BA (2007) C-jun-N-terminal kinase regulates adenosine A1 receptor-mediated synaptic depression in the rat hippocampus. Neuropharmacology 53:906-917.

Chen J, Tan Z, Zeng L, Zhang X, He Y, Gao W, Wu X, Li Y, Bu B, Wang W, 
Duan S (2013) Heterosynaptic long-term depression mediated by ATP released from astrocytes. Glia 61:178-191.

Chen Z, Xiong C, Pancyr C, Stockwell J, Walz W, Cayabyab FS (2014) Prolonged adenosine Al receptor activation in hypoxia and pial vessel disruption focal cortical ischemia facilitates clathrin-mediated AMPA receptor endocytosis and long-lasting synaptic inhibition in rat hippocampal CA3-CA1 synapses: differential regulation of GluA2 and GluA1 subunits by p38 MAPK and JNK. J Neurosci 34:9621-9643.

Clifford JJ, Waddington JL (2000) Topographically based search for an ethogram among a series of novel D4 dopamine receptor agonists and antagonists. Neuropsychopharmacology 22:538-544.

Covelo A, Araque A (2018) Neuronal activity determines distinct gliotransmitter release from a single astrocyte. Elife 7:e32237.

Cuenda A, Rousseau S (2007) p38 MAP-kinase pathway regulation, function and role in human diseases. Biochim Biophys Acta 1773:1358-1375.

Davies SP, Reddy H, Caivano M, Cohen P (2000) Specificity and mechanism of action of some commonly used protein kinase inhibitors. Biochem J 351:95-105.

de Mendonça A, Almeida T, Bashir ZI, Ribeiro JA (1997) Endogenous adenosine attenuates long-term depression and depotentiation in the CA1 region of the rat hippocampus. Neuropharmacology 36:161-167.

Feng Y, Wen J, Chang CC (2009) p38 mitogen-activated protein kinase and hematological malignancies. Arch Pathol Lab Med 133:1850-1856.

Fujii S, Saito K, Miyakawa H, Ito K, Kato H (1991) Reversal of long-term potentiation (depotentiation) induced by tetanus stimulation of the input to CA1 neurons of guinea pig hippocampal slices. Brain Res 555:112-122.

Fujii S, Sekino Y, Kuroda Y, Sasaki H, Ito K, Kato H (1997) 8-cyclopentyltheophylline, an adenosine A1 receptor antagonist, inhibits the reversal of long-term potentiation in hippocampal CA1 neurons. Eur J Pharmacol 331:9-14.

Fujii S, Kuroda Y, Ito K, Kaneko K, Kato H (1999) Effects of adenosine receptors on the synaptic and EPSP-spike components of long-term potentiation and depotentiation in the guinea-pig hippocampus. J Physiol (London) 521:451-466.

Fujii S, Kato H, Ito K, Itoh S, Yamazaki Y, Sasaki H, Kuroda Y (2000) Effects of $\mathrm{A} 1$ and $\mathrm{A} 2$ adenosine receptor antagonists on the induction and reversal of long-term potentiation in guinea pig hippocampal slices of CA1 neurons. Cell Mol Neurobiol 20:331-350.

Ho S, Clipstone N, Timmermann L, Northrop J, Graef I, Fiorentino D, Nourse J, Crabtree GR (1996) The mechanism of action of cyclosporine A and FK506. Clin Immunol Immunopathol 80:S40-S45.

Huang CC, Liang YC, Hsu KS (1999) A role for extracellular adenosine in time-dependent reversal of long-term potentiation by low-frequency stimulation at hippocampal CA1 synapses. J Neurosci 19:9728-9738.

Huang CC, Liang YC, Hsu KS (2001) Characterization of the mechanism underlying the reversal of long term potentiation by low frequency stimulation at hippocampal CA1 synapses. J Biol Chem 276:48108-48117.

Izumi Y, Zorumski CF (1993) Nitric oxide and long-term synaptic depression in the rat hippocampus. Neuroreport 4:1131-1134.

Izumi Y, Zorumski CF (2008) Direct cortical inputs erase LTP at Schaffer collateral synapses. J Neurosci 28:9557-9563.

Izumi Y, Zorumski CF (2016) GABA and endocannabinoids mediate depotentiation of Schaffer collateral synapses induced by stimulation of temperoammonic inputs. PLoS One 11:e0149034.

Izumi Y, Zorumski CF (2017) Neuregulin and dopamine D4 receptors contribute independently to depotentiation of Schaffer collateral LTP by temperoammonic path stimulation. eNeuro 4:ENEURO.0176-17.2017.

Izumi Y, Clifford DB, Zorumski CF (1992) Inhibition of long-term potentiation by NMDA-mediated nitric oxide release. Science 257:1273-1276.

Izumi Y, Tokuda K, Zorumski CF (2008) Long-term potentiation inhibition by low-level N-methyl-D-aspartate receptor activation involves calcineurin, nitric oxide and p38 mitogen-activated protein kinase. Hippocampus 18:258-265.

Izumi Y, O’Dell KA, Zorumski CF (2013) Metaplastic LTP inhibition after LTD induction in CA1 hippocampal slices involves NMDA receptormediated neurosteroidogenesis. Physiol Rep 1:e00133.

Kandel ER, Dudai Y, Mayford MR (2014) The molecular and systems biology of memory. Cell 157:163-186.

Kato K, Li ST, Zorumski CF (1999) Modulation of LTP induction in the hippocampus by NMDA-mediated presynaptic inhibition. Neuroscience 92:1261-1272.

Koeberle SC, Romir J, Fischer S, Koeberle A, Schattel V, Albrecht W, Grütter C,
Werz O, Rauh D, Stehle T, Laufer SA (2011) Skepinone-L is a selective p38 mitogen-activated protein kinase inhibitor. Nat Chem Biol 8:141-143.

Kwon OB, Paredes D, Gonzalez CM, Neddens J, Hernandez L, Vullhorst D, Buonanno A (2008) Neuregulin-1 regulates LTP at CA1 hippocampal synapses through activation of dopamine D4 receptors. Proc Natl Acad Sci U S A 105:15587-15592.

Malenka RC, Bear MF (2004) LTP and LTD: an embarrassment of riches. Neuron 44:5-21.

McCluskey A, Sim AT, Sakoff JA (2002) Serine-threonine protein phosphatase inhibitors: development of potential therapeutic strategies. J Med Chem 45:1151-1175.

Mrzljak L, Bergson C, Pappy M, Huff R, Levenson R, Goldman-Rakic PS (1996) Localization of dopamine D4 receptors in GABAergic neurons of the primate brain. Nature 381:245-248.

Neddens J, Buonanno A (2010) Selective populations of hippocampal interneurons express ErbB4 and their number and distribution is altered in ErbB4 knockout mice. Hippocampus 20:724-744.

Nicoll RA (2017) A brief history of long-term potentiation. Neuron 93:281-290.

Pascual O, Casper KB, Kubera C, Zhang J, Revilla-Sanchez R, Sul JY, Takano H, Moss SJ, McCarthy K, Haydon PG (2005) Astrocytic purinergic signaling coordinates synaptic networks. Science 310:113-116.

Root DH, Hoffman AF, Good CH, Zhang S, Gigante E, Lupica CR, Morales M (2015) Norepinephrine activates dopamine D4 receptors in the rat lateral habenula. J Neurosci 35:3460-3469.

Sánchez-Soto M, Bonifazi A, Cai NS, Ellenberger MP, Newman AH, Ferré S, Yano H (2016) Evidence for noncanonical neurotransmitter activation: norepinephrine as a dopamine D2-like receptor agonist. Mol Pharmacol 89:457-466.

Santschi LA, Zhang XL, Stanton PK (2006) Activation of receptors negatively coupled to adenylate cyclase is required for induction of long-term synaptic depression at schaffer collateral-CA1 synapses. J Neurobiol 66:205-219.

Serrano A, Haddjeri N, Lacaille JC, Robitaille R (2006) GABAergic network activation of glial cells underlies hippocampal heterosynaptic depression. J Neurosci 26:5370-5382.

Shamir A, Kwon O-B, Karavanova I, Vullhorst D, Leiva-Salcedo E, Janssen MJ, Buonanno A (2012) The importance of the NRG-1/ErbB4 pathway for synaptic plasticity and behaviors associated with psychiatric disorders. J Neurosci 32:2988-2997.

Smith CC, Greene RW (2012) CNS dopamine transmission mediated by noradrenergic innervation. J Neurosci 32:6072-6080.

Staubli U, Chun D (1996) Proactive and retrograde effects on LTP produced by theta pulse stimulation: mechanisms and characteristics of LTP reversal in vitro. Learn Mem 3:96-105.

Swanson LW, Hartman BK (1975) The central adrenergic system: an immunofluorescence study of the location of cell bodies and their efferent connections in the rat utilizing dopamine- $\beta$-hydroxylase as a marker. J Comp Neurol 163:467-505.

Tokuda K, O'Dell KA, Izumi Y, Zorumski CF (2010) Midazolam inhibits hippocampal long-term potentiation and learning through dual central and peripheral benzodiazepine receptor activation and neurosteroidogenesis. J Neurosci 30:16788-16795.

Turrigiano G (2011) Too many cooks? Intrinsic and synaptic homeostatic mechanisms in cortical circuit refinement. Annu Rev Neurosci 34:89-103.

Vullhorst D, Neddens J, Karavanova I, Tricoire L, Petralia RS, McBain CJ, Buonanno A (2009) Selective expression of ErbB4 in interneurons, but not pyramidal cells, of the rodent hippocampus. J Neurosci 29:12255-12264.

Woo RS, Li XM, Tao Y, Carpenter-Hyland E, Huang YZ, Weber J, Neiswender H, Dong XP, Wu J, Gassmann M, Lai C, Xiong WC, Gao TM, Mei L (2007) Neuregulin-1 enhances depolarization-induced GABA release. Neuron 54:599-610.

Zhang JM, Wang HK, Ye CQ, Ge W, Chen Y, Jiang ZL, Wu CP, Poo MM, Duan S (2003) ATP released by astrocytes mediates glutamatergic activity-dependent heterosynaptic suppression. Neuron 40:971-982.

Zhang L, Zhang P, Wang G, Zhang H, Zhang Y, Yu Y, Zhang M, Xiao J, Crespo P, Hell JW, Lin L, Huganir RL, Zhu JJ (2018) Ras and rap signal bidirectional synaptic plasticity via distinct subcellular microdomains. Neuron 98:783-800.e4

Zorumski CF, Izumi Y (2012) NMDA receptors and metaplasticity: mechanisms and possible roles in neuropsychiatric disorders. Neurosci Biobehav Rev 36:989-1000. 